\title{
Evidence of meteorite impact-induced thermal shock in quartz
}

\section{K. Ernstson}

University of Würzburg, 97074 Würzburg, Germany; kernstson@ernstson.de

\section{Introduction}

Thermal shock is a mechanical load caused by a rapid change of temperature (heating or cooling) in a material that may fracture if the stress exceeds its tensile strength. While thermal shock plays an important role in material sciences and in industrial production, it has rarely been considered in impact cratering. A priori, this is easily understood, because hypervelocity impact shock producing the wellknown rock and mineral deformations (shock metamorphism) precedes a thermal shock on pressure release. However, if the shock pressures are enough to melt or vaporize target rocks (beginning at a few tens of $\mathrm{GPa}$ ), then on rapid contact of melt or vapor with less or no shocked rocks in the immediately following excavation stage, extreme thermal shock can be expected to exert mechanical load and a kind of secondary shock fracturing. Here, I report on observations in quartz of shocked impactites with evidence of strong thermal shock fracturing and of ballen quartz formation by thermal shock, the latter originally suggested in a recent paper [1].

\section{Quartz microfracturing}

Very unusual microfracture patterns in quartz have been observed to occur in meteorite impact rocks in a manner so far not described in the literature to our knowledge (Fig. 1). The polymictic impact breccia in Fig. 1A comes from the recently proposed impact event in the Czech Republic [2, 3]. Individual small quartz grains are distributed throughout the matrix in most cases not contacting each other (Fig. 1, B) but revealing extreme mosaic-like microfracturing Fig. 1, C-F). In many of the grains this microfracturing is more or less sharply limited to a concentric rim zone encasing a largely untouched core with a few sub-planar fractures in some cases. Multiple sets of true planar features (PFs) known as an impact shock effect also occur (Fig. 1, C). Similarly unusual quartz fracturing has been reported also from the Nalbach-Saarland impact event [4] where abundant isolated quartz grains in an impact melt glass are observed, as is the case for the recently described granitic impact melt rock sheet in SE Bavaria [5]. In all three cases a tec-
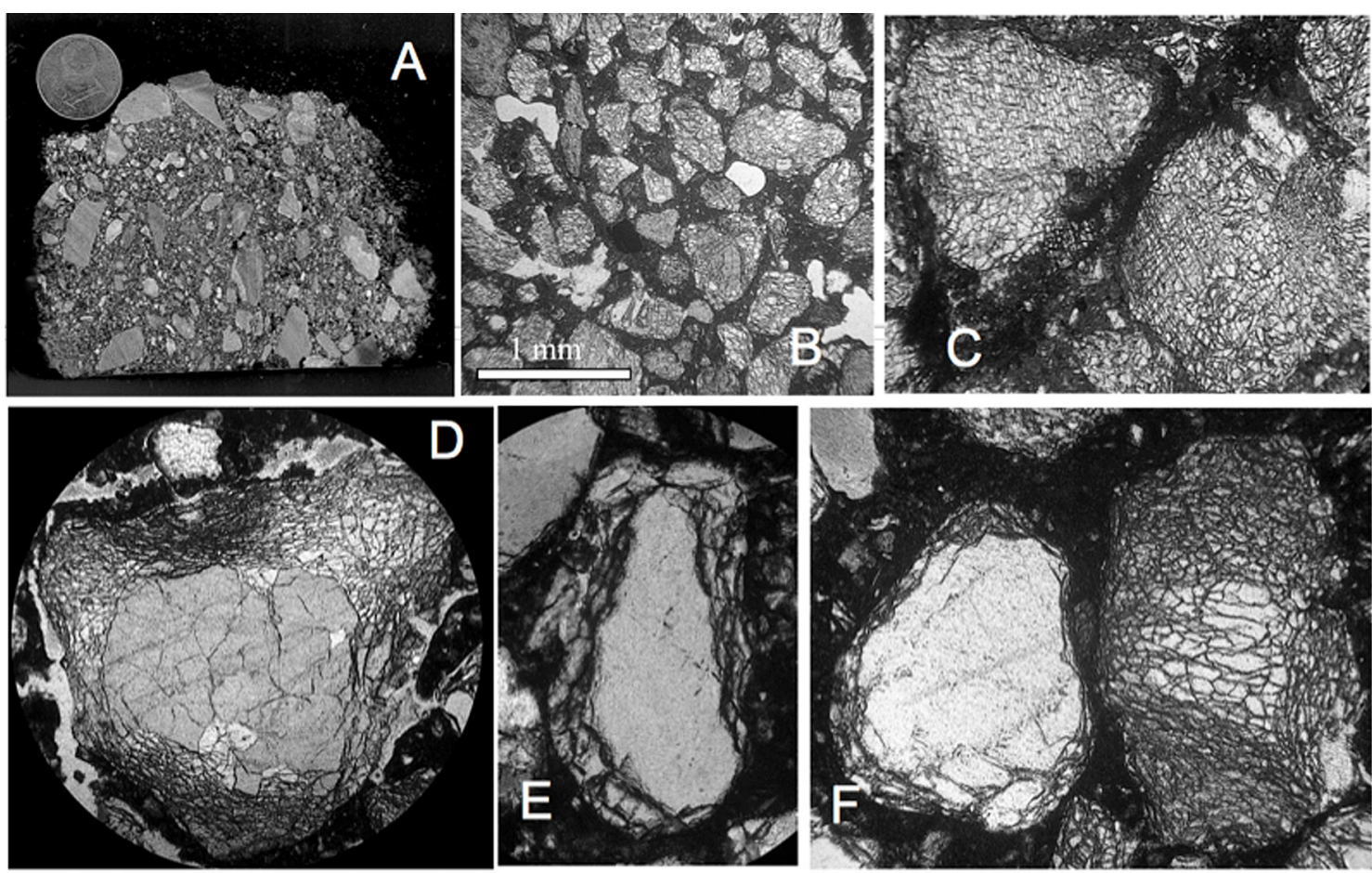

Fig. 1. A: Polymictic impact breccia from the Czech impact site [2, 3]. B: Close-up of the breccia showing intensely fractured quartz grains that are floating in the breccia matrix without contacts. C: Selected quartz grains from the breccia matrix with multiple sets of planar fractures (PFs, densely developed cleavage). D-F: Quartz grains from the breccia matrix exhibiting the spectacularly fractured rim regions around a widely untouched core with some planar and subplanar fractures. B-F: Thin section photomicrographs, crossed polarizers 

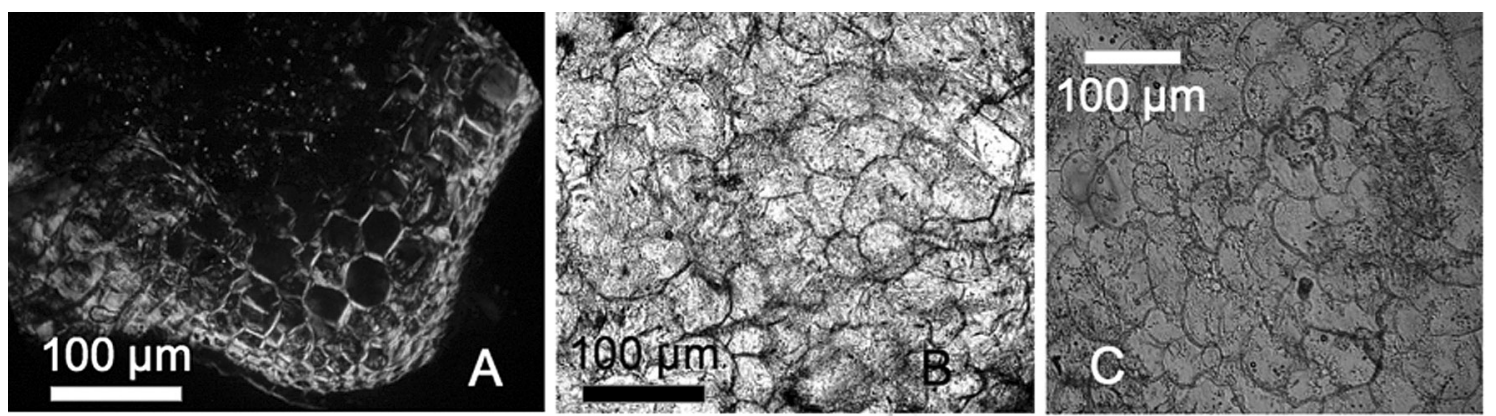

Fig. 2. Silica ballen structures as a shock indicator. A: Czech impact; ballen as diaplectic silica glass [3]. B: Shocked granitic melt rock sheet near Bach/Regensburg (Bavaria, Germany) [5]. C: Saarland impact (Germany) [4]. Photomicrographs, A crossed polarizers, B, C plane light

tonic origin and a direct shock-wave microfracturing can reasonably be excluded.

\section{Ballen structures}

Ballen structures in silica form a characteristic texture in quartz that in general is considered a result from various stages of phase transformation and recrystallization of amorphous silica like e. g., diaplectic glass and hence are regarded as shock indicator (e. g., [6]). A different model has recently been suggested [1] that proposes a formation of ballen in quartz in an extreme thermal shock event. This idea has been taken up and is here shown to be a probable indicator of impact thermal shock in other impact events (Fig. 2).

\section{Discussion and conclusion}

The presented here results of thin section analyses of quartz shocked in three young impact events in the Czech Republic and in Germany reveal observations strongly supporting processes of thermal shock that in the past have in general been disregarded in impact cratering research. Noticeably, in all three impact events both effects the extremely strange microfracturing and the ballen quartz formation occur together with impact melt glass and diaplectic silica and, hence, point to affinity. In particular the micro-fractured quartz grains «floating» isolated in the matrix imply high confining pressure for maintaining coherence, and the microfracturing limited to a rim all around the grains can best, and probably only, be explained by a sudden complete immersion in rock melt and/or vapor shortly after shock wave passage, experiencing extreme thermal shock heating and rapid cooling. The bal- len quartz formation fits well into this process and emphatically supports the model presented in [1]. Hence, thermal shock should become a more considered feature in future impact cratering research.

\section{References}

1. Chanou, A., Grieve, R. A. F., Osinski, G. R. Formation of ballen in silica by thermal shock // Bridging the Gap III: Impact Cratering In Nature, Experiments, and Modeling. 2015. 21-26 September. University of Freiburg, Germany. LPI Contribution 1861. P. 1112.

2. Molnár, M., Ventura, K., Švanda, P., Štaffen, Z., Rappenglück, M.A., Ernstson, K. Chrudim - Pardubice: Evidence for a Young Meteorite Impact Strewn Field in the Czech Republic // 48th Lunar and Planetary Science Conference. 2017. 1920.

3. Molnár, M., Švanda, P., Beneš, L., Ventura, K., Ernstson, K. Asphaltic (bituminous) breccias with carbolite (carbon allotrope) and ballen structures in silica as indicative of thermal shock: more evidence of a Holocene meteorite impact event in the Czech Republic // 49th Lunar and Planetary Science Conference. 2017. 1423.

4. Ernstson, K., Müller, W., Gawlik-Wagner, A. The Saarlouis semi crater structure: notable insight into the Saarland (Germany) meteorite impact event achieved // 49th Lunar and Planetary Science Conference. 2018. 191876.

5. Ernstson, K., Poßekel, J., Rappenglück, M.A. Nearground airburst cratering: petrographic and ground penetrating radar (GPR) evidence for a possibly enlarged Chiemgau impact event (Bavaria, SE Germany) // 51st Lunar and Planetary Science Conference. 2020. 1231.

6. Ferrière, L., Koeberl, C., Reimold, W. U. Characterisation of ballen quartz and cristobalite in impact breccias: new observations and constraints on ballen formation // Eur. J. Mineralogy. 2009. V. 21. P. 203-217. 